\title{
EFFECT OF EARLY ADMINISTRATION OF CAFFEINE AND LOW-DOSE HYDROCORTISONE ON TRACHEAL ASPIRATE INTERLEUKIN (IL)- 8 AND IL-10 LEVELS IN VERY PRETERM INFANTS
}

\author{
D. Dobryanskyy ${ }^{1}$, O. Borysiuk ${ }^{1,2}$, Z. Salabay ${ }^{2}$, Y. Dubrovna ${ }^{2}$ \\ ${ }^{1}$ Paediatrics, L'viv National Medical University, ${ }^{2}$ Neonatal Intensive Care Unit, L'viv Regional Clinical \\ Hospital, L'viv, Ukraine
}

Caffeine and steroids have been linked to a decrease in the incidence of bronchopulmonary dysplasia (BPD) in extremely premature infants, and one of the possible mechanisms of their action could be modulation of inflammation. In a randomised study we evaluated the effect of early administration of caffeine and hydrocortisone on tracheal aspirate (TA) IL-8 and IL-10 levels.

Methods: 100 very preterm newborns on mechanical ventilation were randomly assigned on the first day of life to one of the 2 groups depending on administration of caffeine and hydrocortisone. 46 infants with gestational age of 27,89 (1,95) wks. were treated and 54 newborns of $28,32(1,83)$ wks. formed the control group. TA was taken at enrolment and after about $55 \mathrm{hrs}$. of treatment. Cytokine levels in TA were determined with enzyme-linked immunosorbent assay.

Results: Initial values of interleukins were similar in the both groups but at mean age of approximately 65 hrs. IL- 8 and IL-10 concentrations were significantly lower in infants treated with caffeine and hydrocortisone $(26205,00 \mathrm{pg} / \mathrm{mL}$ [IR - 880,00] and $129,95 \mathrm{pg} / \mathrm{mL}$ [IR - 129,95] vs. $26896,71 \mathrm{pg} / \mathrm{mL}$ [IR $461,29]$ and $483,88 \mathrm{pg} / \mathrm{mL}$ [IR - 303,88] accordingly; $\mathrm{p}<0,001)$. The reliable reduction of IL-8 content was observed in treated infants and significant increase of IL-10 concentration was found in control newborns. It was no significant difference in BPD rates between the groups.

Conclusions: Our data suggest that early administration of caffeine and hydrocortisone may inhibit production of IL-8 and IL-10 in immature lungs not preventing, however, BPD development. 